\title{
Liderazgo en el Centro Médico ABC
}

\section{ABC Medical Center leadership}

\author{
Juan Manuel Fernández Vázquez*
}

«En contra de la opinión de mucha gente, los líderes no nacen, se hacen a través del esfuerzo y el trabajo»

Vince Lombardi

En este primer número de 2020 de nuestra revista el énfasis en el liderazgo, la presencia de las mujeres en el Centro Médico ABC y los diferentes artículos sobre el manejo integral de problemas en mano, entre otros, ponen de manifiesto lo que el liderazgo significa para nosotros como grupo.

El médico debe ser creativo, visionario, compañero, mentor, generador de confianza y de integridad, humanista que entiende a sus pacientes y a sus acompañantes en el manejo diagnóstico, terapéutico y pronóstico; con sus colaboradores atento, consejero, saber escuchar, alentar y sobre todo compartir con ellos los éxitos, problemas y resultados no satisfactorios. Los cursos de liderazgo en el Centro Médico $\mathrm{ABC}$ nos ayudan a promover con empatía estos conocimientos.

El feminismo en el Centro Médico ABC ha sido fomentado desde sus inicios, cuando Annie Cass (Lady
Cowdray) fundó el Sanatorio Inglés, por las enfermeras que fueron traídas desde Inglaterra, el personal de intendencia fundamentalmente femenino, la escuela de enfermería y de fisioterapia, la presencia de enfermeras, la administración y por las médicas en diferentes puestos de jerarquía y especialización. Las mujeres en el patronato también han significado un factor importante en la trascendencia y liderazgo de nuestra institución.

Durante la Segunda Guerra Mundial el Dr. Sterling Bunnell (1882-1957) hizo de la cirugía de mano un área de especial interés debido a la gran cantidad de heridas de guerra y sus secuelas. Enfatizó la concurrencia de conocimientos de especialidades en ortopedia, cirugía plástica y neurocirugía para la atención adecuada de estas lesiones. En 1944 publicó la primera edición de su libro Surgery of the hand. En nuestro hospital, los cirujanos de mano deben terminar primero un entrenamiento completo en ortopedia o en cirugía plástica para después dedicar un año a la cirugía de mano y desde hace varios años, como elección, un segundo año a la cirugía de hombro o de codo, microcirugía y endoscopia o cirugía de mano en pediatría.

\footnotetext{
* Ortopedia y Cirugía de Mano, FACCS.

Recibido para publicación: 03/03/2020. Aceptado: 04/03/2020.

Correspondencia:

Juan Manuel Fernández Vázquez

Av. Carlos Graef Fernández Núm. 154, $5^{\circ}$ piso, consultorio 501,

Col. Tlaxala, 05300, Cuajimalpa de Morelos, CDMX.

Tel: 16647154

E-mail: fernandezvazquez@yahoo.com
} 